\title{
The Effect of Cold Rolling on the Hydrogen Susceptibility of 5083 Aluminum Alloy
}

\author{
E.P. Georgiou ${ }^{1,2, *}$, J.-P. Celis ${ }^{1}$ and C.N. Panagopoulos ${ }^{3}$
}

1 Department Materials Engineering (MTM), K.U. Leuven, Kasteelpark Arenberg 44, B-3001 Leuven, Belgium; jean-pierre.celis@kuleuven.be

2 Falex Tribology N.V., Wingepark 23B, B3110 Rotselaar, Belgium

3 Laboratory of Physical Metallurgy, National Technical University of Athens, Zografos, 15780 Athens, Greece; chpanag@metal.ntua.gr

* Correspondence: emmanuel.georgiou@mtm.kuleuven.be or egeorgiou@falex.eu; Tel.: +32-1632-1292 or $+32-1640-7965$

Received: 27 September 2017; Accepted: 23 October 2017; Published: 25 October 2017

\begin{abstract}
This work focuses in investigating the effect of cold deformation on the cathodic hydrogen charging of 5083 aluminum alloy. The aluminium alloy was submitted to a cold rolling process, until the average thickness of the specimens was reduced by $7 \%$ and $15 \%$, respectively. A study of the structure, microhardness, and tensile properties of the hydrogen charged aluminium specimens, with and without cold rolling, indicated that the cold deformation process led to an increase of hydrogen susceptibility of this aluminum alloy.
\end{abstract}

Keywords: cold rolling; aluminum alloy; hydrogen embrittlement; mechanical properties

\section{Introduction}

The growing importance of hydrogen among the alternative energy sources has given rise to new studies concerning its effect on the technological properties of metallic alloys [1-4]. Among these materials, aluminum alloys are extensively used as structural materials in the nuclear industry, and thus are continuously exposed to harsh conditions that involve the interaction of hydrogen uptake and mechanical loading. In particular, it has been reported [5-7] that most aluminum-magnesium alloys are sensitive to hydrogen embrittlement. However, the mechanism of hydrogen incorporation into such aluminum alloys has not yet been unequivocally established [8]. Among the many proposed mechanisms [8], the most accepted are the traditional dislocation pinning theory first suggested by Troiano in 1960 [9] and followed by Watson et al. in the $80 \mathrm{~s} \mathrm{[10],} \mathrm{and} \mathrm{the} \mathrm{"hydrogen} \mathrm{enhanced} \mathrm{localized}$ plasticity" (HELP) theory first proposed by Beachem in 1972 [11] and confirmed by the research group of Birnbaum et al. [12,13].

The first theory proposes that hydrogen diffuses through easy paths, such as grain boundaries and surface defects, into the surface layers of metallic materials. Hydrogen is then positioned in interstitial sites and reduces the atomic cohesive strength by creating micro-defects. The increase in the concentration and size of these micro-defects leads to strain hardening and possibly to the formation of micro-cracks, which degrade the mechanical properties of the material. On the other hand, HELP theory suggests that hydrogen uptake increases both the density and mobility of dislocations. New dislocations may be generated by a hydrogen concentration gradient, but with increasing difficulty since they are hindered by the existing ones, creating thus dislocation pile-ups. In this way, the trapping rate of dislocations is increased.

The above very complex interactions can be significantly influenced by various factors, such as hydrogen charging conditions [14], heat treatments [15], surface treatments [16], etc. Furthermore, it should be noted that the majority of aluminum alloys are submitted to various forming treatments 
(e.g., rolling, extrusion, etc.) before being used in technological applications. These processes can significantly change the microstructure of the surface layers and subsequently alter the electrochemical and mechanical properties of the material. However, despite the high applicability of wrought alloys and especially aluminum alloys, very little is known about the effect of forming treatments on hydrogen susceptibility $[17,18]$. Thus, this research work focuses in investigating the effect of cold rolling (commonly applied in aluminum alloys [19]) on the hydrogen uptake of 5083 wrought aluminum alloy and in particular its influence on the structure and mechanical properties of this industrial material.

\section{Experimental Procedure}

The material used in this study was a commercially supplied 5083 wrought aluminum alloy ( $95.2 \mathrm{wt} \% \mathrm{Al}, 3.5 \mathrm{wt} \% \mathrm{Mg}, 0.5 \mathrm{wt} \% \mathrm{Mn}, 0.3 \mathrm{wt} \% \mathrm{Si}, 0.26 \mathrm{wt} \% \mathrm{Cr}, 0.24 \mathrm{wt} \% \mathrm{Fe}$ ). Aluminum alloy sheets with dimensions of $50 \mathrm{~cm} \times 30 \mathrm{~cm} \times 0.3 \mathrm{~cm}$ were submitted to a cold rolling process, in a Mario Di Maio LS630x350 cold rolling mill (Mario Di Maio, Milan, Italy), until their average thickness was reduced by $7 \%$ and $15 \%$ respectively with one pass. The rolling mill speed was $10 \mathrm{~m} / \mathrm{min}$. From these plates, a number of microhardness and standard tensile specimens were produced. In order to ensure a similar surface topography, all aluminum alloy specimens were ground by $\mathrm{SiC}$ papers with increasing finishes and polished with $3 \mu \mathrm{m}$ diamond paste. The resulting average roughness was approximately $0.4 \mu \mathrm{m}$. After the preparation of the specimens, a stress relief procedure was performed, by annealing at $350{ }^{\circ} \mathrm{C}$ for $2 \mathrm{~h}$ and then slowly cooling at room temperature, in an automatic furnace with $\mathrm{Ar}$ inert atmosphere.

Hydrogen was introduced into the aluminum alloy specimens by electrolytic cathodic charging. This procedure was performed in a solution consisting 75 vol $\% \mathrm{CH}_{3} \mathrm{OH}, 22.4$ vol $\% \mathrm{H}_{2} \mathrm{O}$ and $2.6 \mathrm{vol} \% \mathrm{H}_{2} \mathrm{SO}_{4}$, poisoned with $\mathrm{As}_{2} \mathrm{O}_{3}(0.1 \mathrm{~g} / \mathrm{L})$ as hydrogen recombination inhibitor, at room temperature. The hydrogen charging conditions were kept constant for all the experiments: charging current density $30 \mathrm{~mA} / \mathrm{cm}^{2}$ and charging time $6 \mathrm{~h}$. Graphite electrodes were used as anodes. The experimental parameters selected in this work are based on optimized conditions for this electrolyte [5,7]. The aim is to have sufficient time to form hydrides without having extensive blistering.

Metallographic observation of the grain structure of 5083 aluminum alloy before and after the rolling process was performed in a Jevanert Metallurgical Microscope (MM) (Zeiss, Oberkochen, Germany), after chemical etching with Graff's reagent $\left(84 \mathrm{~mL} \mathrm{H}_{2} \mathrm{O}, 15.5 \mathrm{~mL} \mathrm{HNO}\right.$, $0.5 \mathrm{~mL} \mathrm{HF}$, $3 \mathrm{~g} \mathrm{Cr}_{2} \mathrm{O}_{3}$ ) for $90 \mathrm{~s}$ and analyzed with Image Pro Plus Software (4.5, Media Cybernetics, Rockville, MD, United States). Structural study of the cathodically charged aluminum alloy specimens was performed with a Siemens/Bruker D 5000 X-ray diffractometer (Bruker, Billerica, MA, United States), with Cu Ka radiation and a graphite monochromator. Mechanical testing was carried out immediately after charging in order to minimize the loss of hydrogen. All the tension tests were performed at a strain rate of $3.3 \times 10^{-4} \mathrm{~s}^{-1}$, at room temperature. Microhardness tests were conducted with a Shimadju Vickers indenter (Shimadju, Kyoto, Japan), imposing $0.15 \mathrm{~N}$ for $15 \mathrm{~s}$. The given values of the experimental parameters presented are the mean value of five independent experiments.

\section{Results and Discussion}

Structural characterization of the as-received and hydrogen charged 5083 aluminum alloy, without and with $15 \%$ cold rolling by means of $X$-ray diffraction revealed that the as-received specimen consisted of an aluminum solid solution, whereas in the hydrogen charged specimens aluminum hydride $\left(\mathrm{AlH}_{3}\right)$ was also formed, Figure 1. The presence of aluminum hydride in the surface layers of the hydrogen charged aluminum alloy was a result of increased hydrogen concentration, which excided the solubility limit of hydrogen in the aluminum matrix (0.0001 at \% [20]). In addition, a slight increase in aluminum hydride peak intensity was observed for the aluminum alloy with $15 \%$ cold rolling in comparison to the aluminum solid solution peaks. 


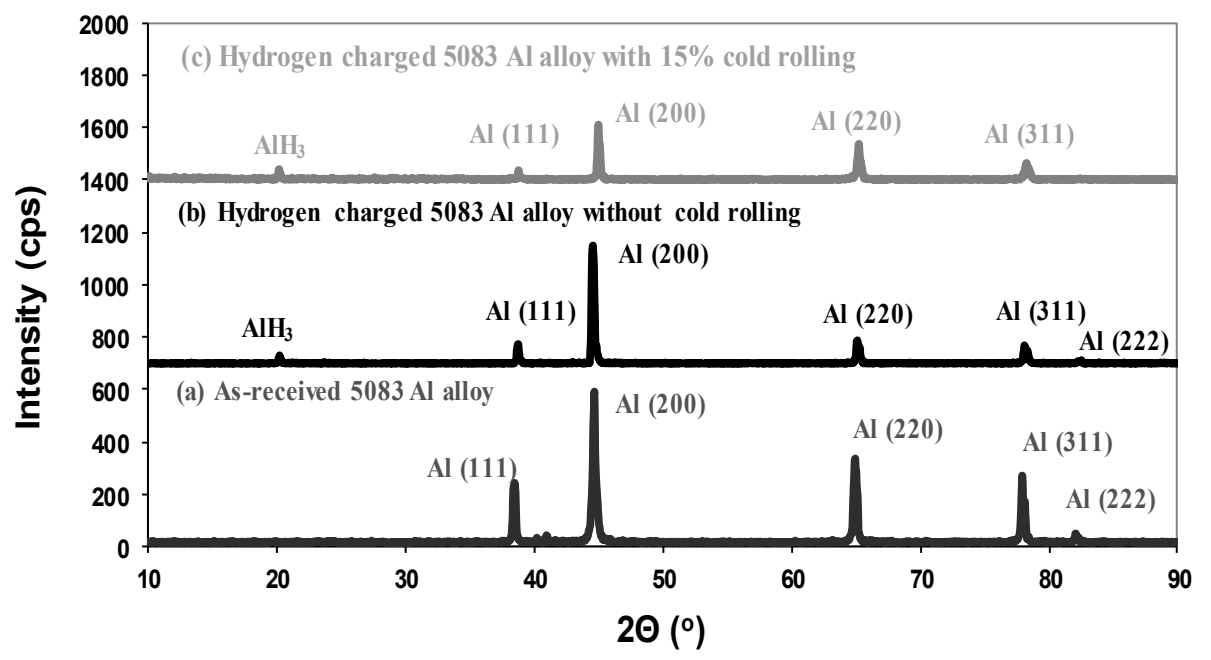

Figure 1. XRD spectrogram of (a) as-received 5083 aluminum specimen; (b) hydrogen charged aluminum specimen without cold rolling, at $30 \mathrm{~mA} / \mathrm{cm}^{2}$ current density and for $6 \mathrm{~h}$, and (c) hydrogen charged aluminum specimen with $15 \%$ cold rolling, at $30 \mathrm{~mA} / \mathrm{cm}^{2}$ current density for $6 \mathrm{~h}$.

It is known that cold rolling processes can lead to the formation of various micro-defects, such as micro-pits, oil-pits, grooves, and scratches [21]. However, these micro-defects can act as 'easy paths', through which the hydrogen can diffuse from the surface layers to the deeper layers of 5083 aluminum alloy, in a cathodic hydrogen process. A high concentration of diffusion pathways per materials' volume, is believed to increase the diffusivity of hydrogen into the surface layers of a cold rolled material [22]. In addition, the grain size of metallic materials is alleged to have a significant role in the cathodic hydrogen charging process. In fact, Chou and Tsai [23] observed that the hydrogen susceptibility of 2205 duplex stainless steels is strongly dependent on the grain size of the material. Their results indicated that both the effective diffusivity and the susceptibility of hydrogen embrittlement were higher for the finer grain size stainless steel specimen. Indeed, during cold rolling of 5083 aluminum alloy a decrease of the average grain size was observed, Figure 2 . The average grain size was found to be: $48 \mu \mathrm{m}$ for the alloy without rolling, $40 \mu \mathrm{m}$ for the alloy with $7 \%$ cold rolling, and $34 \mu \mathrm{m}$ for the alloy with $15 \%$ cold rolling. Thus, according to the previous investigators, the finer the grain size, the higher the hydrogen susceptibility of the material.

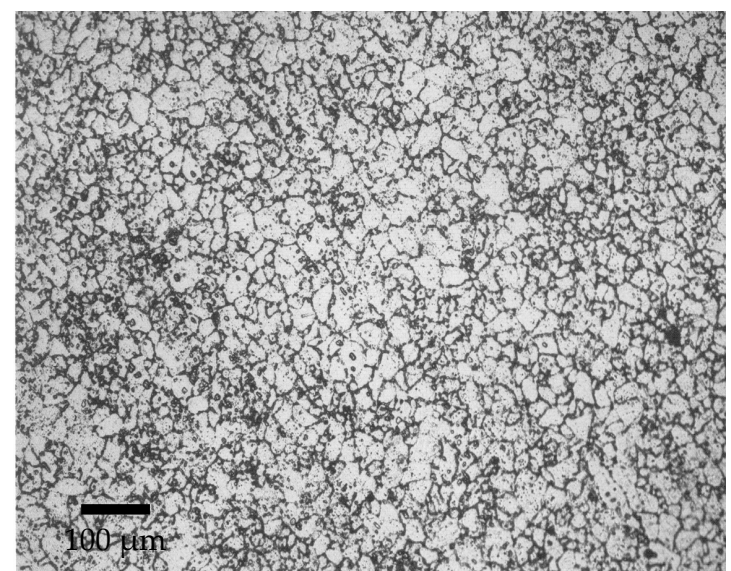

(a)

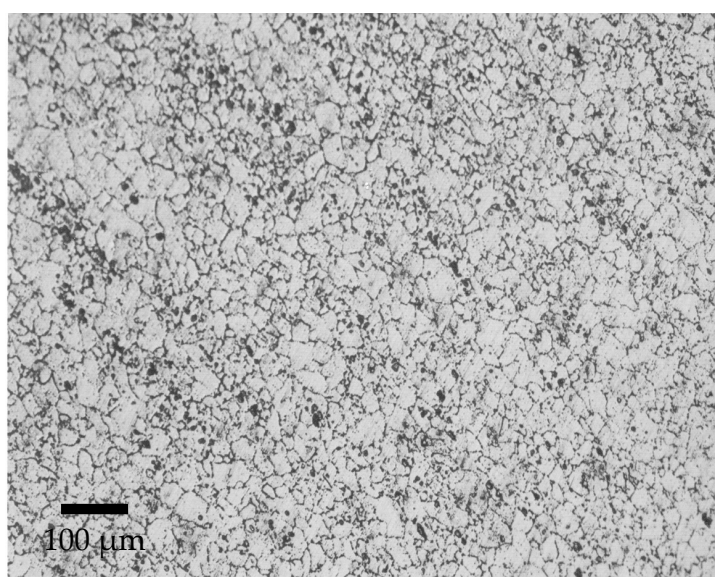

(b)

Figure 2. Cont. 


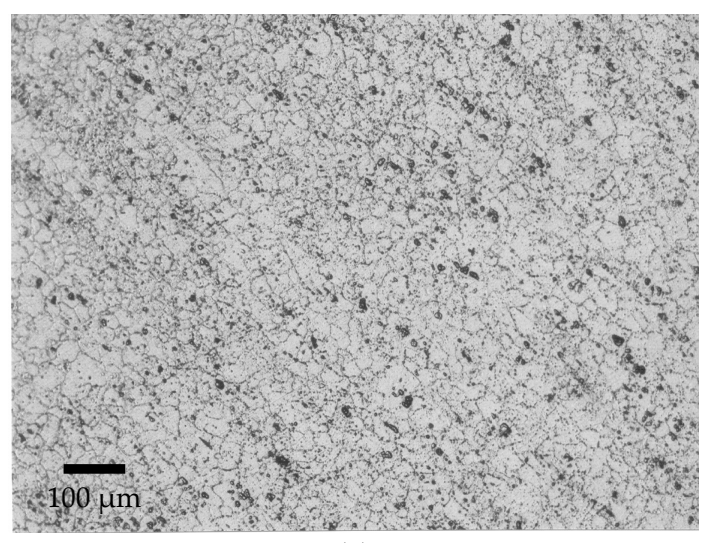

(c)

Figure 2. Grain structure of surface layers of (a) as-received; (b) with 7\% cold rolling; and (c) with 15\% cold rolling 5083 aluminum alloy after chemical etching with Graff's reagent.

Microhardness tests on the cross section of charged aluminum specimens, with and without cold rolling, revealed a surface hardening due to hydrogen uptake with respect to the as-received material, Figure 3. The increase of the microhardness in the surface layers of the hydrogen charged alloys, can be either explained in terms of dislocation pinning mechanism $[9,10]$ or based on the hydrogen enhanced localized plasticity (HELP) theory $[12,13]$. According to the first theory, hydrogen diffuses through easy paths, such as grain boundaries, into the surface layers of the alloy. Hydrogen is positioned in interstitial sites [24] and reduces the atomic cohesive strength by creating micro-defects. Recent research [25] on the fundamental work of Fukai and Ōkuma [26] showed that hydrogen atoms in interstitial positions can interact with vacancies and stabilize them by forming hydrogen-vacancy complexes. The number of hydrogen-vacancy complexes is increased during deformation of the material, whereas with time they tend to agglomerate and act as nuclei for the formation of nano-voids [25]. In any case, the increase in the concentration and size of these defects leads to strain hardening and subsequently increases the surface hardness of the alloy. According to the HELP theory, the solute hydrogen atoms often act as dislocation pinning sites, since they locally increase the density of dislocations and create dislocation pile-ups [12,13].

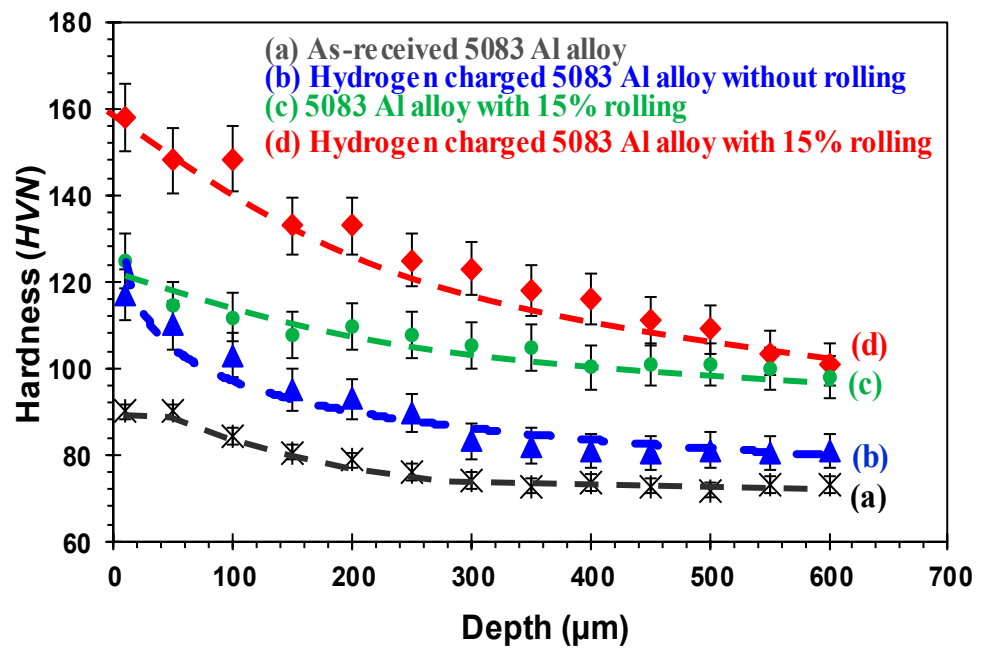

Figure 3. Hardness profile of (a) as-received 5083 aluminum alloy, (b) hydrogen charged 5083 aluminum alloy without cold rolling $\left(30 \mathrm{~mA} / \mathrm{cm}^{2}\right.$ for $6 \mathrm{~h}$ ), (c) 5083 aluminum alloy with $15 \%$ cold rolling, and $(\mathrm{d})$ hydrogen charged 5083 aluminum alloy with $15 \%$ cold rolling $\left(30 \mathrm{~mA} / \mathrm{cm}^{2}\right.$ for $\left.6 \mathrm{~h}\right)$, as a function of diffusion depth. 
In addition, it was also observed that the cold rolling of 5083 aluminum alloy led to higher microhardness values with respect to the as-received material, due to strain hardening of the surface layers. By comparing the microhardness profile of the cold rolled samples with and without hydrogen charging it can be seen that an additional increase of the surface hardness is recorded. An estimation of the increase of microhardness in the case of the sample without cold rolling showed that, the incorporation of hydrogen into the surface layers of this alloy increased the surface hardness by approximately $18 \%$, whereas in the case of the $15 \%$ cold rolled alloy this increase was in the range of $22 \%$. This observation is probably attributed to the increased hydrogen concentration in the surface layers of the alloy. In particular, it is believed that cold rolling results in a higher number of defects (e.g., vacancies, dislocations) per materials volume of the rolled samples in comparison to the as-received. These defects act as diffusion pathways and trapping sites for hydrogen atoms and thus accelerate the hydrogen uptake process.

To get a better insight on the effect of cold rolling on the uptake of hydrogen, the diffusion coefficient for the hydrogen charged alloys with and without cold rolling was calculated. It has been found $[5,7]$ that the distribution profile of microhardness (see Figure 3) can be seen as an approximation of the diffusion profile of hydrogen in the material and as an approximate result of Fick diffusion mechanism [5,7]. Therefore, the diffusion coefficient $D$ can be calculated, by the mathematical equation:

$$
D=x^{2} /(4 t)
$$

where $D$ is the diffusion coefficient $\left(\mathrm{m}^{2} \cdot \mathrm{s}^{-1}\right), x$ is the diffusion length $(\mathrm{m})$ of hydrogen in the surface layers of the examined aluminum specimen, obtained from Figure 3, and $t$ is the charging time (s). From the above equation the diffusion coefficient of $5083 \mathrm{Al}$ alloy without cold rolling was $7 \times 10^{-13} \mathrm{~m}^{2} \cdot \mathrm{s}^{-1}$, whereas with $15 \%$ cold rolling the diffusion coefficient was $1 \times 10^{-12} \mathrm{~m}^{2} \cdot \mathrm{s}^{-1}$. This result also confirms the hypothesis that cold rolling increases the uptake of hydrogen in metallic materials.

Typical stress-strain curves of the as-received and hydrogen charged 5083 aluminum alloy, with and without cold rolling, are presented in Figure 4. From this figure, it can be seen that the ultimate tensile strength (UTS) of the hydrogen charged alloy with and without cold rolling are similar $(\approx 287 \mathrm{MPa})$. In any case, their UTS was slightly higher than that of the as-received sample (276 MPa). This behavior can be explained by the occurrence of two antagonistic phenomena during hydrogen uptake. On one hand, the hardness and subsequently the UTS $(\sigma \approx 2.9 \mathrm{HV})$ of the alloy increases by the dislocation pinning mechanisms [27], whereas on the other hand the formation of micro-cracks and blisters (see Figure 5) degrades the mechanical properties of the material [28]. Thus, depending on balance between these two phenomena, a different behavior in the UTS can be observed.

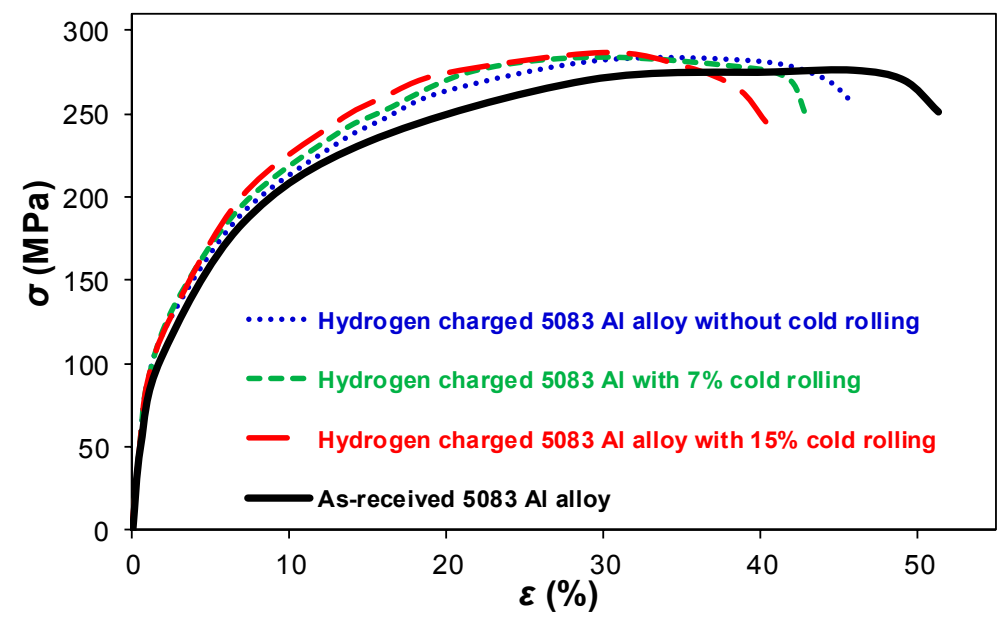

Figure 4. Stress-strain curves for the as-received 5083 aluminum alloy and the hydrogen charged alloy without cold rolling, with $7 \%$ cold rolling and with $15 \%$ cold rolling, charged at $30 \mathrm{~mA} / \mathrm{cm}^{2}$ for $6 \mathrm{~h}$. 


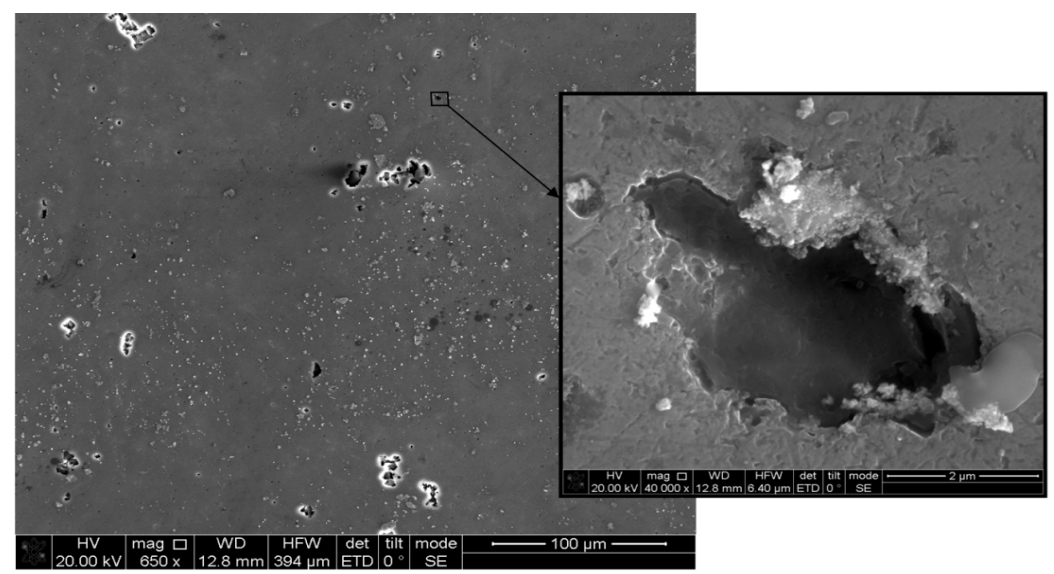

Figure 5. Formation of localized blisters on the surface of $5083 \mathrm{Al}$ alloy after hydrogen charging at $30 \mathrm{~mA} / \mathrm{cm}^{2}$ for $6 \mathrm{~h}$.

The ductility of all hydrogen charged samples was significantly lower than that of the as-received alloy. In addition, the higher the degree of cold rolling the more intense the embrittlement (indicated clearly by drop of ductility). In particular, the ductility of 5083 aluminum alloy (under the selected charging and tensile test conditions) dropped from $51.4 \%$ to $46 \%$ (10\% decrease of ductility in comparison to as-received) when hydrogen was introduced. This drop is even more pronounced for the hydrogen charged samples with cold rolling, as the ductility further decreased to $43 \%$ ( $16.5 \%$ decrease of ductility in comparison to as-received) and $40.5 \%$ (22.3\% decrease of ductility in comparison to as-received) for $7 \%$ and $15 \%$ of cold rolling. Therefore, cold deformation has a significant effect on the embrittlement of this alloy. This observation is believed to be the result of the higher diffusion and trapping of hydrogen in the rolled alloys, as explained previously. Indeed, the absorbed hydrogen atoms can hinder the movement of dislocations and thus decrease the ductility of the alloy, whereas the presence of blisters and micro-cracks on the surface of the alloy [27] further decrease the ductility [28] of this material.

The fracture behavior of hydrogen charged 5083 aluminum specimens, without cold rolling and with $7 \%$ and $15 \%$ cold rolling after tensile testing, was studied with the aid of a scanning electron microscope. A typical morphology of the fractured surface of hydrogen charged aluminum alloy without rolling is shown in Figure 6a. In this fractograph, the following fracture patterns can be observed. In the outer area a distinctive brittle fracture can be seen, in the form of cleavage (area indicated by light blue arrow in Figure 6a). In the deeper surface layers of the hydrogen affected zone, a mixed fracture mode which consists of brittle transcrystalline cleavage (flat surface patterns indicated by yellow arrows in Figure 6a) and intergranular ductile fracture identified by microvoids/dimples (red arrows in Figure 6a) was observed. The bulk layers of this specimen show a typical intergranular ductile fracture again by formation of dimples (red arrows in Figure 6a). The observed brittle patterns are believed to be the result of both pinning of dislocations by the solute hydrogen atoms and to the formation and fracture of aluminum hydrides. Indeed, as explained before, interstitial hydrogen atoms act as dislocation pinning sites, since they locally increase the density of dislocations and create dislocation pile-ups [12,13]. In addition, the brittle cleavage patterns observed in Figure 6 can be explained in terms of the "stress induced hydride formation" mechanism [29,30], where cracks are propagated from the repeated formation of hydrides (due to mechanical stresses) and to their subsequent cleavage. A similar fracture pattern was observed for the hydrogen charged $5083 \mathrm{Al}$ alloy with $7 \%$ and $15 \%$ cold rolling, Figure $6 \mathrm{~b}, \mathrm{c}$ respectively. However, it was found that the increase of cold rolling percentage resulted in a larger hydrogen affected zone. This observation is again linked to the fact that forming processes increase the number of lattice defects per material volume, which act as hydrogen trapping sites and increase the solubility of hydrogen in the material. 


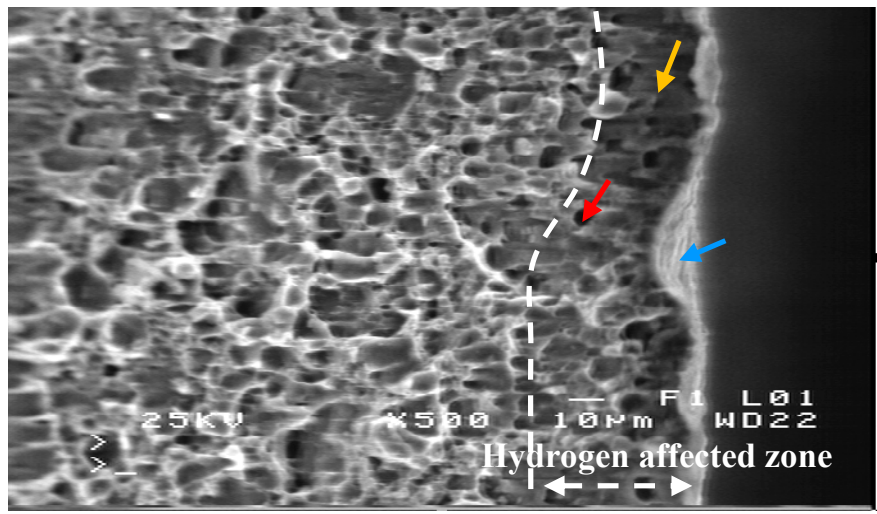

(a)

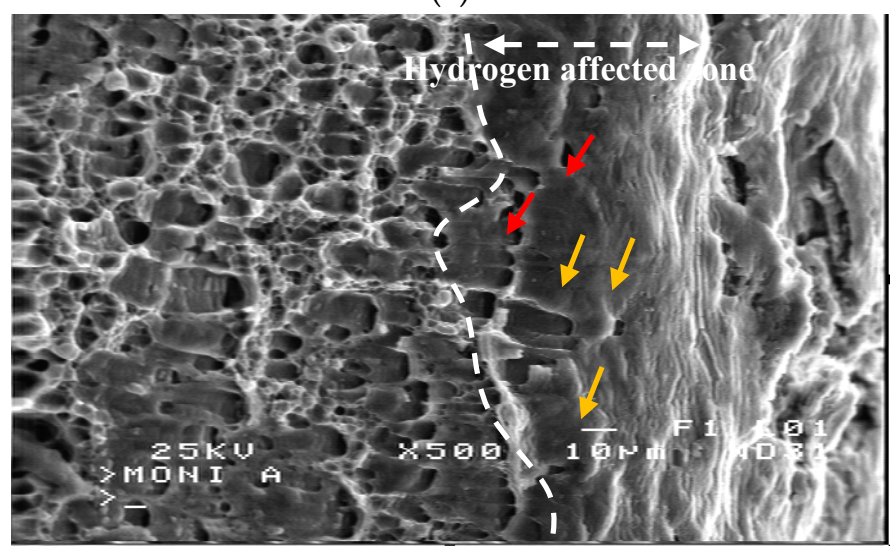

(b)

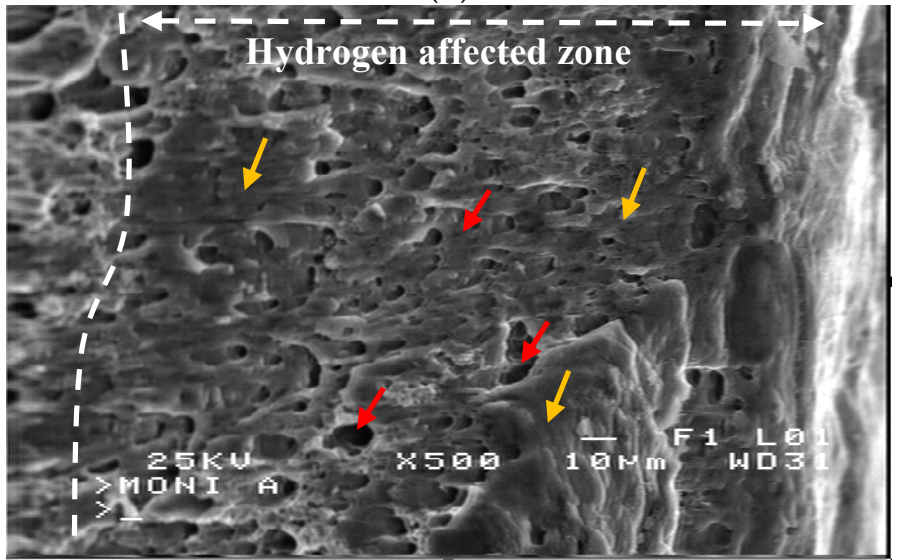

(c)

Figure 6. SEM micrograph of the fractured surface of hydrogen charged 5083 aluminum alloy (a) without cold rolling deformation; (b) with 7\% cold rolling deformation; and (c) with $15 \%$ cold rolling deformation. Charging conditions: $30 \mathrm{~mA} / \mathrm{cm}^{2}$ for $6 \mathrm{~h}$.

\section{Conclusions}

From this experimental work on the effect of cold rolling on the hydrogen uptake of 5083 aluminum alloy, the following conclusions were made:

1. $\mathrm{AlH}_{3}$ hydrides were detected on the surface layers of 5083 aluminum alloy with and without cold rolling, meaning that hydrogen concentration was above the solubility limit of hydrogen in the aluminum matrix. 
2. The tensile tests revealed that the ductility of hydrogen charged 5083 aluminum alloy significantly decreased with increasing rolling deformation, for the examined charging and testing conditions. This is attributed to the higher number of micro-defects in the surface layers of the rolled alloys, which act as "trapping sites" and "diffusion paths" for hydrogen atoms.

3. The ultimate tensile strength of the hydrogen charged alloy was observed to be approximately independent of the rolling process.

4. All hydrogen charged samples exhibited a mixed fracture pattern with brittle transcrystalline cleavage along with ductile intergranular fracture at their surface layers, whereas only ductile intergranular fracture was observed at the bulk of the alloy.

Acknowledgments: This work was part of a FP7 research project SUPERSO-NIC (contract number FP7-NMR-2008-LARGE-2-CP-IP-228814-2), the Scientific Community on Surface Modification of Materials funded by FWO-Flanders, and an EU funded IRSES project (Oil \& Sugar contract IRSES-GA-2011-295202). Training courses and discussions on this topic were held within the EU funded COST MP1407 'E-MINDS' network.

Author Contributions: C.N.P. conceived and designed the experiments; E.P.G. and C.N.P. wrote the paper; C.N.P., J.-P.C. and E.P.G. analyzed the data; E.P.G. performed the experiments.

Conflicts of Interest: The authors declare no conflict of interest.

\section{References}

1. Züttel, A. Materials for hydrogen storage. Mater. Today 2003, 6, 24-33. [CrossRef]

2. Schlapbach, L.; Züttel, A. Hydrogen-storage materials for mobile applications. Nature 2001, 414, 353-358. [CrossRef] [PubMed]

3. Zaluska, A.; Zaluski, L.; Ström-Olsen, J.O. Nanocrystalline magnesium for hydrogen storage. J. Alloys Compd. 1999, 288, 217-225. [CrossRef]

4. Cicconardi, S.P.; Jannelli, E.; Spazzafumo, G. Hydrogen energy storage: Hydrogen and oxygen storage subsystems. Int. J. Hydrogen Energy 1997, 22, 897-902. [CrossRef]

5. Panagopoulos, C.N.; Georgiou, E.P.; Lagaris, D.A. Cathodic Hydrogen Charging of Aluminium Alloys. In Aluminum Alloys: Preparation, Properties and Applications; Persson, E.L., Ed.; Nova Science Publishers Inc.: New York, NY, USA, 2011.

6. Jones, R.H. The influence of hydrogen on the stress-corrosion cracking of low-strength Al-Mg alloys. JOM 2003, 55, 42-46. [CrossRef]

7. Panagopoulos, C.N.; Georgiou, E.P. The effect of hydrogen charging on the mechanical behaviour of 5083 wrought aluminum alloy. Corros. Sci. 2007, 49, 4443-4451. [CrossRef]

8. Robertson, I.M.; Sofronis, P.; Nagao, A.; Martin, M.L.; Wang, S.; Gross, D.W.; Nygren, K.E. Hydrogen embrittlement understood. Metall. Mater. Trans. B 2015, 46, 1085-1103. [CrossRef]

9. Troiano, A. The role of hydrogen and other interstitials in the mechanical behavior of metals. Trans. Am. Soc. Met. 1960, 52, 54-80. [CrossRef]

10. Watson, J.W.; Shen, Y.Z.; Meshii, M. Effect of cathodic charging on the mechanical properties of aluminum. Metall. Trans. A 1988, 19, 2299-2304. [CrossRef]

11. Beachem, C.D. A new model for hydrogen-assisted cracking. Metall. Trans. A 1972, 3, 441-455. [CrossRef]

12. Birnbaum, H.K.; Sofronis, P. Hydrogen-enhanced localized plasticity-A mechanism for hydrogen-related fracture. Mater. Sci. Eng. A 1994, 176, 191-202. [CrossRef]

13. Robertson, I.M. The effect of hydrogen on dislocation dynamics. Eng. Fract. Mech. 2001, 68, 671-692. [CrossRef]

14. Panagopoulos, C.N.; Georgiou, E.P.; Chaliampalias, D. Cathodic hydrogen charging of zinc. Corros. Sci. 2014, 79, 16-20. [CrossRef]

15. Hardwick, D.A.; Thompson, A.W.; Bernstein, I.M. The effect of copper content and heat treatment on the hydrogen embrittlement of 7050-type alloys. Corros. Sci. 1988, 28, 1127-1137. [CrossRef]

16. Wilde, B.E.; Manohar, M.; Albright, C.E. The influence of laser surface melting on the resistance of AISI 4135 low alloy steel to hydrogen-induced brittle fracture. Mater. Sci. Eng. A 1995, 198, 43-49. [CrossRef]

17. Amira, S.; Huot, J. Effect of cold rolling on hydrogen sorption properties of die-cast and as-cast magnesium alloys. J. Alloys Compd. 2012, 520, 287-294. [CrossRef] 
18. Marquez, J.A.; Matsushima, I.; Uhlig, H.H. Effect of cold rolling on resistance of Ni-Fe alloys to hydrogen cracking. Corrosion 1970, 26, 315-322. [CrossRef]

19. Metals Handbook, Properies and Selection of Non-Ferrous Alloys, 9th ed.; ASM: Metals Park, OH, USA, 1985.

20. Qiua, C.; Opalkab, S.M.; Olsonc, G.B.; Anton, D.L. Thermodynamic modeling of the sodium alanates and the Na-Al-H system. Int. J. Mater. Res. 2006, 97, 1484-1494. [CrossRef]

21. Kenmochi, K.; Yarita, I.; Abe, H.; Fukuhara, A.; Komatu, T.; Kaito, H. Effect of micro-defects on the surface brightness of cold-rolled stainless-steel strip. J. Mater. Proc. Technol. 1998, 69, 106-111. [CrossRef]

22. Misra, R.D.K.; Akhtar, D. Effect of cold work on hydrogen embrittlement susceptibility of $\mathrm{Ni}_{60} \mathrm{Nb}_{40}$ glass. Mater. Res. Bull. 1986, 21, 1473-1479. [CrossRef]

23. Chou, S.L.; Tsai, W.T. Effect of grain size on the hydrogen-assisted cracking in duplex stainless steels. Mater. Sci. Eng. A 1999, 270, 219-224. [CrossRef]

24. Fukai, Y. Site preference of interstitial hydrogen in metals. J. Less-Common Met. 1984, 101, 1-16. [CrossRef]

25. Li, S.; Li, Y.; Lo, Y.-C.; Neeraj, T.; Srinivasan, R.; Ding, X.; Sun, J.; Qi, L.; Gumbsch, P.; Li, J. The interaction of dislocations and hydrogen-vacancy complexes and its importance for deformation-induced proto nano-voids formation in $\alpha$-Fe. Int. J. Plast. 2015, 74, 175-191. [CrossRef]

26. Fukai, Y.; Ōkuma, N. Evidence of copious vacancy formation in Ni and Pd under high hydrogen pressure. Jpn. J. Appl. Phys. 1993, 32, 1256-1259. [CrossRef]

27. Panagopoulos, C.N.; El-Amoush, A.S.; Agathocleous, P.E. Hydrogen-induced cracking and blistering in $\alpha$-brass. Corros. Sci. 1998, 40, 1837-1844. [CrossRef]

28. Panagopoulos, C.N.; Papapanayiotou, P. The influence of cathodic hydrogen charging on the mechanical behaviour of Al-4Zn-1Mg alloy. J. Mater. Sci. 1995, 30, 3449-3456. [CrossRef]

29. Lufrano, J.; Sofronis, P.; Birnbaum, H.K. Elastoplastically accommodated hydride formation and embrittlement. J. Mech. Phys. Solids 1998, 46, 1497-1520. [CrossRef]

30. Eliezer, D.; Tal-Gutelmacher, E.; Boellinghaus, T. Hydrogen embrittlement in hydride and non-hydride forming systems-microstructural/phase changes and cracking mechanisms. In Proceedings of the 11th International Conference on Fracture (ICF11), Turin, Italy, 20-25 March 2005.

(C) 2017 by the authors. Licensee MDPI, Basel, Switzerland. This article is an open access article distributed under the terms and conditions of the Creative Commons Attribution (CC BY) license (http:/ / creativecommons.org/licenses/by/4.0/). 